\title{
The MAPK/ERK Cascade Targets Both Elk-1 and cAMP Response Element-Binding Protein to Control Long-Term Potentiation- Dependent Gene Expression in the Dentate Gyrus In Vivo
}

\author{
Sabrina Davis, ${ }^{1}$ Peter Vanhoutte, ${ }^{2}$ Christiane Pagès, ${ }^{2}$ Jocelyne Caboche, ${ }^{2}$ and Serge Laroche ${ }^{1}$ \\ 'Laboratoire de Neurobiologie de l'Apprentissage, de la Mémoire, et de la Communication, Centre National de la \\ Recherche Scientifique (CNRS), Unité Mixte de Recherche (UMR) 8620, Université Paris Sud, 91405 Orsay, France, and \\ 2Laboratoire de Neurochimie-Anatomie, Institut des Neurosciences, CNRS UMR 7624, Universtité Pierre et Marie Curie, \\ 75005 Paris, France
}

The mitogen-activated protein kinase/extracellular signalregulated kinase (MAPK/ERK) signaling cascade contributes to synaptic plasticity and to long-term memory formation, yet whether MAPK/ERK controls activity-dependent gene expression critical for long-lasting changes at the synapse and what the events underlying transduction of the signal are remain uncertain. Here we show that induction of long-term potentiation (LTP) in the dentate gyrus in vivo leads to rapid phosphorylation and nuclear translocation of MAPK/ERK. Following a similar time course, the two downstream transcriptional targets of MAPK/ERK, cAMP response element-binding protein (CREB) and the ternary complex factor Elk-1, a key transcriptionalregulator of serum response element (SRE)-driven gene expression, were hyperphosphorylated and the immediate early gene zif268 was upregulated. The mRNA encoding MAP kinase phosphatase MKP-1 was upregulated at the time point when

At many synapses, brief bursts of tetanic stimulation trigger calcium influxes into the postsynaptic neuron and induce a persistent increase in synaptic strength. This form of synaptic plasticity, known as long-term potentiation (LTP), is widely accepted as a candidate cellular mechanism for the storage of information (Bliss and Collingridge, 1993). In the hippocampus, a brain structure implicated in several forms of learning, LTP can last for many hours or as long as days or weeks (Barnes, 1979; Doyère and Laroche, 1992). The longer-lasting phases of LTP require the transcription of genes and the synthesis of proteins during a critical period (Otani et al., 1989; Nguyen et al., 1994; Frey and Morris, 1997). Within the first few hours of LTP, there is activation of specific immediate early genes (IEGs) (Cole et al., 1989; Wisden et al., 1990) encoding transcription factors that interact with promoter regulatory elements of a host of downstream effector genes. A crucial event in signal transduction leading to gene regulation in neurons is the activation of protein kinases.

Received Feb. 24, 2000; revised March 30, 2000; accepted March 31, 2000.

This work was supported in part by a grant from Institut Lilly to J.C. P.V. is a doctoral fellow of the Ministere de l'Education Nationale et de l'Enseignement Supérieur. We thank M. Rogard for technical assistance. We are grateful to J. M. Trzaskos, J. L. Hytrek, A. C. Tabaka, J. S. Piecara, and C. Teleha for the generous gift of SL327.

Correspondence should be addressed to J. Caboche, Laboratoire de Neurochimie-Anatomie, Institut des Neurosciences, Centre National de la Recherche Scientifique, Unité Mixte de Recherche 7624, Universtité Pierre et Marie Curie, 9 quai St. Bernard, 75005 Paris, France. E-mail: jocelyne.caboche@snv.jussieu.fr.

Copyright $\odot 2000$ Society for Neuroscience $0270-6474 / 00 / 204563-10 \$ 15.00 / 0$
MAPK/ERK phosphorylation had returned to basal levels, suggesting a negative feedback loop to regulate deactivation of MAPK/ERK. We also show that inhibition of the MAPK/ERK cascade by the MAPK kinase MEK inhibitor SL327 prevented CREB and Elk-1 phosphorylation, and LTP-dependent gene induction, resulting in rapidly decaying LTP. In conclusion, we suggest that Elk-1 forms an important link in the MAP kinase pathway to transduce signals from the cell surface to the nucleus to activate the genetic machinery necessary for the maintenance of synaptic plasticity in the dentate gyrus. Thus, MAPK/ERK activation is required for LTP-dependent transcriptional regulation and we suggest this is regulated by two parallel signaling pathways, the MAPK/ERK-Elk-1 pathway targeting SRE and the MAPK/ERK-CREB pathway targeting CRE.

Key words: hippocampus; LTP; MAPK/ERK; Elk-1 phosphorylation; zif268; transcriptional regulation

Several kinases, including PKC, PKA, $\alpha$ calcium/calmodulindependent kinase II ( $\alpha \mathrm{CaMKII})$ and the tyrosine kinases have been implicated in LTP (Soderling and Derkach, 2000). Recent work suggests that the mitogen-activated protein kinase/ extracellular-regulated kinase (MAPK/ERK) cascade, a complex kinase cascade implicated in cell differentiation and proliferation, is essential for long-term synaptic plasticity (English and Sweatt, 1996, 1997) and for certain types of learning (Atkins et al., 1998; Blum et al., 1999). Moreover, there is abundant cross-talk between kinase pathways, suggesting that MAPK/ERK may be a point of convergence integrating PKC, PKA, and CaMK signals (Impey et al., 1998a; Vanhoutte et al., 1999; Roberson et al., 1999), in addition to the activity of individual signaling systems. In cell lines, MAPK/ERK translocates to the nucleus once it has been activated in which it can regulate transcriptional activity of many IEGs (for review, see Treisman, 1996).

In this study, we tested whether MAPK/ERK is activated in LTP in vivo and required for LTP-induced gene expression and investigated how MAPK/ERK controls activity-dependent transcriptional regulation. Recent experiments have suggested that transactivation of the cAMP response element-binding protein (CREB) by MAPK/ERK via the CREB kinase ribosomal protein S6 kinase (Rsk2) plays a role in synaptic plasticity and memory formation (for review, see Impey et al., 1999). For example, using CRE-LacZ transgenic mice, it was shown that LacZ expression was upregulated in the CA1 slice by the induction of LTP (Impey et al., 1996) and during contextual learning (Impey et al., 1998b). 
The other strong potential candidate, however, is the ternary complex factor Elk-1, a prime nuclear substrate of the MAPKs c-Jun N-terminal protein kinase (JNK), p38, and ERK (Treisman, 1995), which plays a pivotal role in IEG induction by various extracellular signals (Hipskind et al., 1991; Marais et al., 1993, 1994). In cell cultures, phosphorylation of Elk-1 by MAPK/ERK strongly potentiates its ability to activate transcription through a ternary complex assembled on the serum response element (SRE), a DNA sequence motif present within the upstream regulatory region of many IEGs (Wasylyk et al., 1998), including zif268 which is strongly upregulated in LTP. Although Elk-1 is expressed in hippocampal neurons (Sgambato et al., 1998a), to date there is no evidence implicating Elk-1 as a mediator of transcriptional induction in LTP.

Here we addressed two questions: first, are MAPK/ERK and Elk-1 activated in a coordinated manner after induction of LTP, and second, is MAPK/ERK activation necessary for Elk-1 phosphorylation and LTP-induced SRE-driven transcription. We demonstrate that induction of LTP in the dentate gyrus in vivo results in a strong and transient phosphorylation of MAPK/ERK in dendrites and nuclei of granule cells and phosphorylation of both CREB and Elk-1 in strict spatiotemporal correspondence with MAPK/ERK activation. Inhibition of MAPK/ERK phosphorylation and nuclear translocation prevents Elk-1 and CREB phosphorylation and LTP-induced transcriptional activation of zif268, resulting in rapidly decaying LTP.

\section{MATERIALS AND METHODS}

Electrophysiology. Male Sprague Dawley rats $(n=73)$ weighing 300-400 gm were anesthetized with urethane carbamate $(1.5 \mathrm{mg} / \mathrm{kg})$, placed in a stereotaxic frame, and maintained at a constant body temperature of $37^{\circ} \mathrm{C}$. Unilateral implantation of electrodes were performed using standard stereotaxic procedures (Laroche et al., 1989). Recording electrodes were lowered into the dentate gyrus (bregma $-4.2 \mathrm{~mm}, 2.5 \mathrm{~mm}$ from midline) under electrophysiological control. Stimulating electrodes were implanted in the angular bundle of the perforant path (bregma $-8.0 \mathrm{~mm}$, $4.4 \mathrm{~mm}$ from midline) to evoke a positive-going response in the hilus of the dentate gyrus. Low-frequency test pulses $(100 \mu \mathrm{sec}, 0.033 \mathrm{~Hz})$ to the perforant path were delivered via a photically isolated constant current unit. Individual stimulus intensities were selected to give a population spike amplitude between 1 and $2 \mathrm{mV}$. After the response in the dentate gyrus had stabilized, a 30 min baseline period was recorded, followed by delivery of a tetanus or a pseudotetanus. Tetanic stimuli consisted of six trains of pulses $(400 \mathrm{~Hz}, 20 \mathrm{msec})$, delivered at a $10 \mathrm{sec}$ interval and repeated six times at an interval of $2 \mathrm{~min}$. Pseudotetanus consisted of six pulses, delivered at a $10 \mathrm{sec}$ interval, repeated six times with an interval of $2 \mathrm{~min}$, to match the tetanus without inducing LTP. To ensure maximal stimulation of the fibers during the tetanus or pseudotetanus, the stimulus intensity was increase during this period. Evoked responses were stored as averages of four for off-line analysis. The maximum slope of the EPSP and amplitude of the population spike were measured as described previously (Laroche et al., 1989). In specified experiments, SL327 (100 $\mathrm{mg} / \mathrm{kg}$ in $100 \%$ DMSO) or DMSO $(100 \%)$ was injected intraperitoneally $1 \mathrm{hr}$ before the tetanus. Experimental procedures were conducted in accordance with the guidelines of Centre National de la Recherche Scientifique and the French Agricultural and Forestry Ministry (decree 87848, license number A91429).

Tissue preparation. Rats were killed at specified times after receiving a tetanus or a pseudotetanus. For in situ hybridization and immunocytochemistry, brains were fixed by intracardiac perfusion of $4 \%$ paraformaldehyde (PFA) in $0.1 \mathrm{M} \mathrm{Na}_{2} \mathrm{HPO}_{4} / \mathrm{NaH}_{2} \mathrm{PO}_{4}$ buffer, $\mathrm{pH} 7.5$ (phosphate buffer). Brains were removed and post-fixed in the same fixative solution for $2 \mathrm{hr}$, washed overnight in $0.1 \mathrm{M}$ phosphate buffer containing $15 \%$ sucrose, and then frozen in isopentane $\left(1 \mathrm{~min}\right.$ at $\left.-25^{\circ} \mathrm{C}\right)$. Sections $(20$ $\mu \mathrm{m})$ were cut on a microtome and then kept in a solution containing $30 \%$ ethylene glycol, $30 \%$ glycerol, $0.1 \mathrm{M}$ phosphate buffer, $0.1 \%$ diethyl pyrocarbonate (Sigma) at $-20^{\circ} \mathrm{C}$ until processed for in situ hybridization or immunohistochemistry. For Western blots, rat brains were rapidly removed, and the dorsal dentate gyrus was dissected on ice and lysed in solubilization buffer (10 mm Tris-Cl, $50 \mathrm{~mm} \mathrm{NaCl}, 1 \%$ Triton X-100, 30 mM sodium pyrophosphate, $50 \mathrm{~mm} \mathrm{NaF}, 5 \mu \mathrm{M} \mathrm{ZnCl}, 100 \mu \mathrm{M} \mathrm{Na}_{3} \mathrm{VO}_{4}$, $1 \mathrm{~mm}$ DTT, $5 \mathrm{~nm}$ okadaic acid, $2.5 \mu \mathrm{g}$ of aprotinin, $2.5 \mu \mathrm{g}$ of pepstatin, $0.5 \mu \mathrm{M}$ PMSF, $0.5 \mathrm{~mm}$ benzamidine, and $2.5 \mu \mathrm{g}$ of leupeptin). Insoluble material was removed by centrifugation $\left(13,000 \mathrm{rpm}\right.$ for $20 \mathrm{~min}$ at $\left.4^{\circ} \mathrm{C}\right)$. Cell lysates [30 or $10 \mu \mathrm{g}$ per lane for the detection of phospho-Elk1 (p-Elk-1) and phospho-ERK (p-ERK), respectively] were separated by $10 \%$ SDS-PAGE before electrophoretic transfer onto polyvinylidene difluoride membrane (ICN Biochemicals, Orsay, France).

Immunocytochemistry and Western blotting. The immunohistochemical procedure for detecting active ERK and Elk-1 proteins were performed as described previously (Sgambato et al., 1998a). Briefly, free-floating sections were rinsed in Tris-buffered saline (TBS) $(0.25 \mathrm{M}$ Tris and $0.5 \mathrm{M}$ $\mathrm{NaCl}, \mathrm{pH} 7.5$ ), incubated for $5 \mathrm{~min}$ in TBS containing $3 \% \mathrm{H}_{2} \mathrm{O}_{2}$ and $10 \%$ methanol, and then rinsed three times for $10 \mathrm{~min}$ each in TBS $(0.1 \mathrm{~mm}$ $\mathrm{NaF}$ was included in all buffers and incubation solutions). After $15 \mathrm{~min}$ incubation in $0.2 \%$ Triton X-100 in TBS, sections were rinsed three times in TBS. These were incubated with the primary antibody (see below) for $72 \mathrm{hr}$ at $4^{\circ} \mathrm{C}$. After three rinses in TBS, sections were incubated for $48 \mathrm{hr}$ at $4^{\circ} \mathrm{C}$ with the secondary biotinylated antibody (anti-IgG) using a dilution twice that of the first antibody in TBS. After washing (three times in TBS), sections were incubated overnight in avidin-biotin-peroxidase complex solution (ABC solution; final dilution 1:50; Vector Laboratories, Burlingame, CA). Sections were then washed two times in TBS and two times in TB (Tris $0.25 \mathrm{M}, \mathrm{pH} 7.5$ ), 10 min each, placed in a solution of TB containing $0.1 \% 3-3^{\prime}$ diaminobenzidine $(50 \mathrm{mg} / 100 \mathrm{ml})$ and developed by adding $\mathrm{H}_{2} \mathrm{O}_{2}(0.02 \%)$. After processing, tissue sections were mounted onto gelatin-coated slides and dehydrated through alcohol to xylene for light microscopic examination. For Western blotting, blots were treated as described previously (Vanhoutte et al., 1999). Briefly, they were saturated (1 hr at room temperature) with BSA (Fraction V; Sigma) $8 \%$ (p-Elk-1) or 5\% (p-ERK and p-CREB) and incubated (overnight at $4^{\circ} \mathrm{C}$ ) with the anti-active antibodies. On the second day, the blots were incubated for $2 \mathrm{hr}$ at room temperature with goat anti-rabbit-horseradish peroxidase-conjugated antibodies before exposure to the ECL substrate.

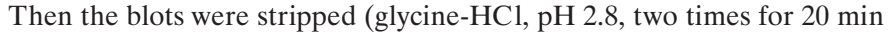
each at $55^{\circ} \mathrm{C}$ ) and saturated overnight in $5 \%$ nonfat dry milk. On the third day, the blots were then incubated with the nonactive antibodies (see below). The efficacy of the stripping step was assessed by omitting the first antibody and verifying the lack of signals on the blot. Anti-active antibodies were polyclonal antibodies raised against the doublephosphorylated $\mathrm{Thr} / \mathrm{Glu} / \mathrm{Tyr}$ region within the catalytic core of the active form of p44/ERK1 and p42/ERK2 (anti-phospho-Thr ${ }^{183}-$ Tyr $^{185}$ ERKs; New England Biolabs, Beverly, MA), a phospho-Ser ${ }^{383}$ peptide corresponding to residues 379-392 of Elk-1 (New England Biolabs), and a phospho-Ser ${ }^{133}$ peptide corresponding to residues $129-137$ of CREB (Upstate Biotechnology, Lake Placid, NY). The dilutions used for immunostaining were 1:200 for p-ERK antiserum; 1:100 for p-Elk-1 antiserum, and 1:200 for p-CREB. For Western blot analysis, the dilutions were 1:2500 for $\mathrm{p}$-ERK antiserum, 1:500 for $\mathrm{p}$-CREB antiserum,1:200 for p-Elk-1, and 1:750 for p-CREB antiserum. For Western blot analysis, the nonactive antibodies used were anti-ERK antibody (1:4000; Tebu, Le Perray en Yvelines, France) and anti-Elk-1 antibody (1:1000, rabbit polyclonal antibody raised against a recombinant protein corresponding to the C-terminal region of human Elk-1) (Janknecht et al., 1994).

In situ hybridization. The antisense (complementary to cellular mRNA) probes were ${ }^{33} \mathrm{P}$-radiolabeled riboprobes. For zif268, and MAP kinase phosphatase (MKP) riboprobes, murine cDNA subclones were used. Zif268 insert corresponding to $1.6 \mathrm{~kb}$ was linearized after HindIII digestion and transcribed with T7 RNA polymerase. The MKP-1 (663 bp) was transcribed with T7 RNA polymerase after linearization with PstI. Transcription reactions contained $1 \mu \mathrm{M} \alpha{ }^{33} \mathrm{P}-\mathrm{UTP}(3000 \mathrm{Ci} / \mathrm{mmol}$; Isotopchim, Peyruis, France), $250 \mu \mathrm{M}$ ATP, CTP, and GTP, and unlabeled UTP $(10.5 \mu \mathrm{M})$, and were incubated at $39^{\circ} \mathrm{C}$ for $2 \mathrm{hr}$. After DNase I digestion, the labeled RNA was purified by phenol/chloroform/isoamyl alcohol (25:24:1) extraction and ethanol precipitation. Gel electrophoresis showed the transcripts to be predominantly full-length. Free-floating sections were mounted on SuperFrost Plus slides (Menzel-Gläser) in RNase-free conditions. Once dried, mounted sections were rinsed in PBS and treated for $10 \mathrm{~min}$ with $0.1 \mathrm{M}$ glycine in $0.1 \mathrm{M}$ Tris-HCl, $\mathrm{pH}$ 7.4. Sections were rinsed for $5 \mathrm{~min}$ at $37^{\circ} \mathrm{C}$ in $0.1 \mathrm{M}$ Tris- $\mathrm{HCl}, \mathrm{pH} 8$, and 50 mM EDTA, and treated for $15 \mathrm{~min}$ at $37^{\circ} \mathrm{C}$ with $1 \mathrm{mg} / \mathrm{ml}$ proteinase $\mathrm{K}$ in the same buffer. Before hybridization, sections were subjected to the following treatment: post-fixation for $15 \mathrm{~min}$ in $4 \%$ PFA and $5 \mathrm{mM} \mathrm{MgCl}_{2}$ in PBS at room temperature, acetylation for $20 \mathrm{~min}$ in acetic anhydride/ 
a

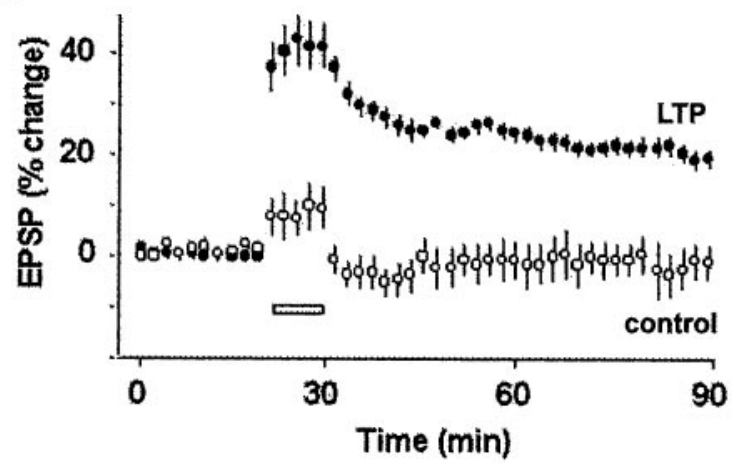

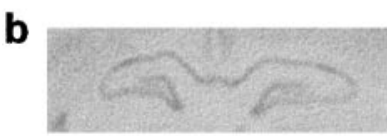

CT 0

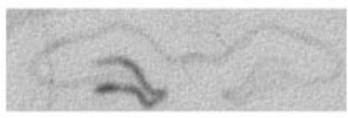

LTP 15

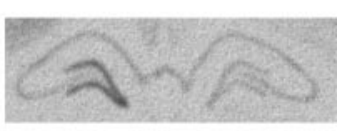

LTP 0

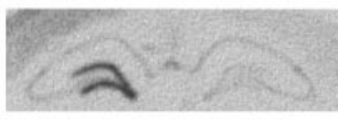

LTP 60
Figure 1. LTP in the dentate gyrus in vivo and corresponding upregulation of zif268 mRNA expression. $a$, The slope of the EPSP is plotted as a percentage change against the baseline before high-frequency tetanic stimulation (LTP) or a pseudotetanus (control). Each point represents an average of four consecutive evoked responses. The white bar indicates the $10 \mathrm{~min}$ period in which the tetanus or the pseudotetanus was delivered. Rats were killed either immediately after the last train of tetani (LTP 0), or 15 (LTP 15) or 60 (LTP 60) min after the tetanus. In rats that were killed immediately after the tetanus, an average of four responses were measured between each tetani. $b$, Autoradiograms shows upregulation of zif268 mRNA at different time points after the induction of LTP compared with control rats $(C T 0)$. There were three to four rats in each group at each of the different time points.

triethanolamine, $\mathrm{pH} \mathrm{8}$, at room temperature, and stepwise dehydration in alcohol. The following hybridization solution was applied to sections, which were then covered with GelBond Film (FMC Bioproducts, Rockland, ME). The hybridization mixture contained $200 \mathrm{ng} / \mathrm{ml}(4 \mathrm{ng} / \mathrm{sec}-$ tion) ${ }^{33} \mathrm{P}-\mathrm{RNA}$ probe in $20 \mathrm{~mm}$ Tris- $\mathrm{HCl}, \mathrm{pH} 8,300 \mathrm{~mm} \mathrm{NaCl}, 5 \mathrm{~mm}$ EDTA, $10 \%$ dextran sulfate, $1 \times$ Denhardt's solution $(0.02 \%$ Ficoll, $0.02 \%$ polyvinyl pyrolidone, and $10 \mathrm{mg} / \mathrm{ml} \mathrm{BSA}), 0.5 \mathrm{mg} / \mathrm{ml}$ E. coli tRNA, $0.1 \mathrm{M}$ DTT, and $50 \%$ formamide. Hybridization was performed at $60^{\circ} \mathrm{C}$ in humid chambers for $16 \mathrm{hr}$. After removing the GelBond coverslips in $4 \times$ SSC $(1 \times$ SSC is $0.15 \mathrm{M} \mathrm{NaCl}-0.015 \mathrm{~m}$ Na citrate $)$ and $10 \mathrm{~mm}$ DTT, the slides were washed in the same solution for $1 \mathrm{hr}$ at room temperature and then in $50 \%$ formamide, $10 \mathrm{~mm}$ Tris- $\mathrm{HCl}, \mathrm{pH} 8,75 \mathrm{~mm}$ $\mathrm{NaCl}$, and $2.5 \mathrm{~mm}$ EDTA. Sections were treated with RNase A (20 $\mu \mathrm{g} / \mathrm{ml}$; Sigma) in $400 \mathrm{~mm} \mathrm{NaCl}, 10 \mathrm{~mm}$ Tris-HCl, $\mathrm{pH} 7.5$, and $50 \mathrm{~mm}$ EDTA for $1 \mathrm{hr}$ at $37^{\circ} \mathrm{C}$ and then rinsed for $15 \mathrm{~min}$ at $60^{\circ} \mathrm{C}$ in $2 \times \mathrm{SSC}$, followed by $0.1 \times$ SSC. After dehydration, sections were air dried and exposed with Biomax MR films (Eastman Kodak, Rochester, NY) for $3 \mathrm{~d}$ (zif268) or $6 \mathrm{~d}$ (for MKP-1 probes).

\section{RESULTS}

\section{Activation of MAPK/ERK and Elk-1 after the induction of LTP}

We induced LTP in the dentate gyrus of adult rats, using a protocol of repeated high-frequency stimulation of the perforant path similar to that used previously to elicit LTP lasting several days in awake animals (Laroche et al., 1989). As expected, the tetanus induced a rapid and stable increase in both the slope of the EPSP $(29.04 \pm 2.29 \%$ ) (Fig. $1 a)$ and the population spike $(392.12 \pm 60.66 \%)$, whereas there was no change in synaptic efficacy in control rats receiving a pseudotetanus (Fig. 1a). Because it is known that LTP in the dentate gyrus can lead to the rapid induction of several immediate early genes (Cole et al., 1989; Wisden et al., 1990), we used in situ hybridization on brain sections from rats killed immediately after the 10 min tetanus (time 0), $15 \mathrm{~min}$ or $1 \mathrm{hr}$ later, to examine the temporal pattern of expression of zif268, an IEG containing four SRE sites on its promoter (Treisman, 1995). In our conditions, there was a strong induction of zif268 mRNA expression in the ipsilateral dentate gyrus in all rats after LTP (Fig. 1b), which was already observed immediately after the end of the tetanus (LTP 0 ) and was sustained for at least $1 \mathrm{hr}$ after LTP. There was only moderate constitutive expression of zif268 in the dentate gyrus at any time point in control rats receiving a pseudotetanus (Fig. 1b). Additional experiments showed that levels of the mRNA was back to baseline levels $3 \mathrm{hr}$ after the induction of LTP (data not shown). Thus, our results are consistent with previous findings (Cole et al., 1989; Wisden et al., 1990) and show that increased expression of zif268 induced by LTP occurs earlier than previously reported.

In the next step, we tested whether the induction of LTP in the dentate gyrus in vivo leads to MAPK/ERK activation and defines its time course of activation. Adjacent sections to those used for in situ hybridization were used for immunocytochemical detection of activated MAPK/ERK proteins using an antibody to the double-phosphorylated form of MAPK (antiphospho-Thr ${ }^{183}$. $\operatorname{Tyr}^{185}$ ERK1/2). A slight p-MAPK/ERK immunostaining was observed in control rats in both the dentate gyrus and CA layers with no difference between the stimulated and nonstimulated sides (Fig. 2), showing that phosphorylation of MAPK/ERK was not influenced by low-frequency stimulation of the perforant path. In sections taken from rats in which LTP was induced, we observed a marked increase in p-MAPK/ERK in the molecular layer and granule cell layer of the dentate gyrus immediately after the induction of LTP, relative to the control side or to rats receiving a pseudotetanus (Fig. 2a). This was a transient increase, because p-MAPK/ERK was no longer detected 15 min later (Fig. 2). Densitometric analysis revealed a significant increase in pMAPK/ERK immediately after the LTP-inducing tetanus (331 $\pm 62 \%, n=4, p<0.05$ relative to the control side) (Fig. 2c). High-magnification microscopy showed numerous p-MAPK/ ERK-immunopositive dentate granule cells after LTP (Fig. $2 b$ ). The increased immunostaining was observed in cytoplasmic compartments and dendrites, suggesting local postsynaptic activation of the protein in the vicinity of the receptors. Upon activation, MAPK/ERK translocates to the nucleus (Chen et al., 1992; Lenormand et al., 1993). The appearance of strong nuclear staining (Fig. $2 b$ ) in numerous granule cells suggests nuclear translocation of activated MAPK/ERK proteins after the induction of LTP. Our results showing the transient activation of MAPK/ ERK immediately after the induction of LTP were confirmed biochemically using Western blot analysis of dorsal dentate gyrus extracts from other groups of animals in each condition (Fig. $2 d$ ). p-MAPK/ERK antibody yielded two bands of 42 and $44 \mathrm{kDa}$ corresponding to ERKs 2 and 1, respectively. Immediately after the 10 min LTP-inducing tetanus, we observed a significant increase in p-ERK1 $(51 \%)$ and p-ERK2 $(280 \%)$ relative to lowfrequency stimulation, suggesting an early activation with the first few trains. This increase reflected MAPK/ERK activation, because total levels of MAPK/ERKs present in tissue extracts were comparable (Fig. $2 d$ ). In concordance with the immunolabeling (Fig. 2a,b), MAPK/ERK1 and ERK2 activation was no longer significantly increased $15 \mathrm{~min}$ after the end of the tetanus (Fig. 
a

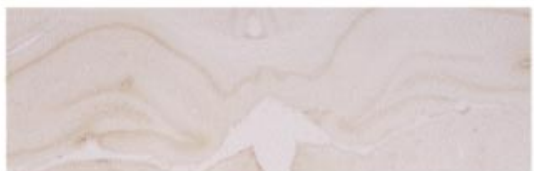

CT 0

b

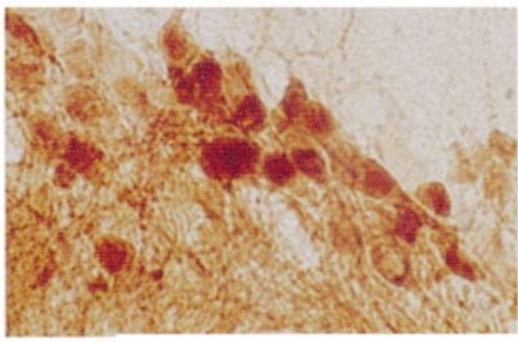

ipsilateral

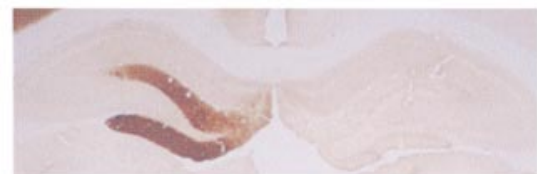

LTP 0

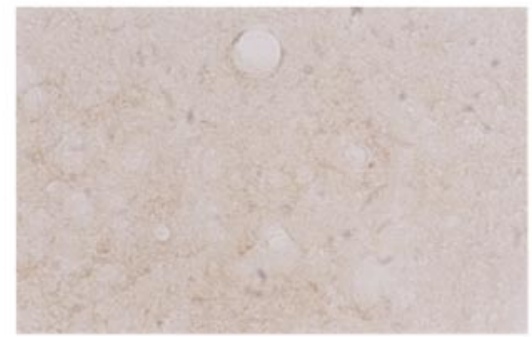

contralateral

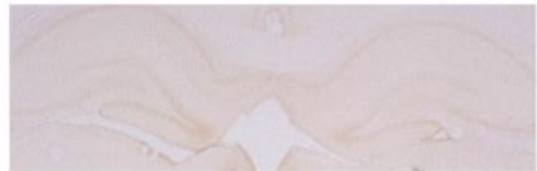

LTP 15

C

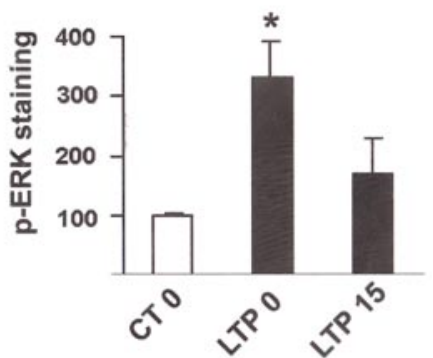

d
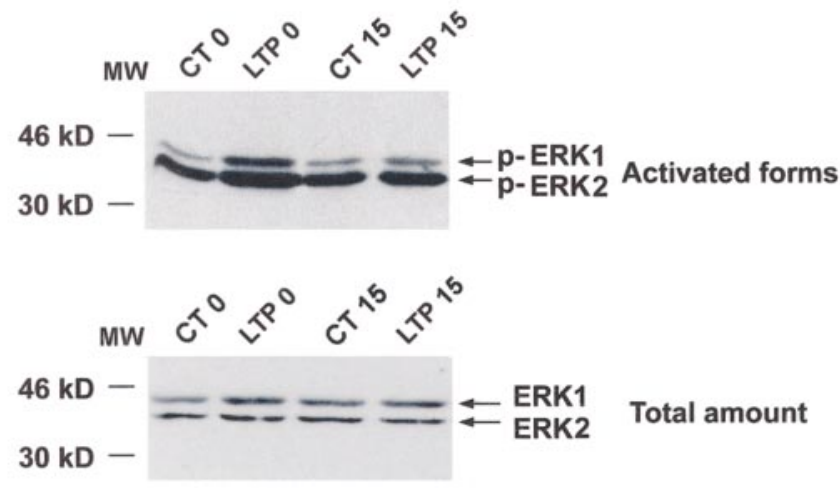

Figure 2. Increase in p-MAPK/ERK after the induction of LTP. $a$, Immunocytochemical images representing p-MAPK/ERK in the ipsilateral dentate gyrus show that it is increased at LTP 0 compared with the contralateral side. No change was observed in the controls or LTP 15. $b$, High magnification $(630 \times)$ of images show p-MAPK/ERK labeling in both cell bodies and dendrites of the granule cells in the ipsilateral dentate gyrus. $c$, Densitometric quantification of immunolabeled sections shows that p-MAPK/ ERK is significantly increased only at LTP $0(p<0.05) . d$, Western blots of p-ERK1 and p-ERK2 confirm immunohistochemical results showing that the increase in p-MAPK/ERK occurs at LTP 0 (top panel), and this increase was only observed with the activated forms (bottom panel).

$2 d$ ). Thus, as demonstrated previously in area CA1 in vitro (English and Sweatt, 1996), LTP in the dentate gyrus in vivo results in a rapid and transient activation of MAPK/ERKs. Activation of the MAPK/ERK1 isoform has not been reported previously, a difference with the present results that may reflect structure specificity (dentate gyrus vs CA1) or a difference between LTP in vivo and in vitro.

The rapid dephosphorylation of MAPK/ERK proteins observed in granule cells of the dentate gyrus after its initial activation in LTP suggests a possible negative feedback control arising from a specific phosphatase. To address this issue, we examined the expression of MKP-1, described in cell lines in vitro as an IEG that is rapidly transcribed by mitogens and translated to inactivate MAPK/ERK (Charles et al., 1993; Sun et al., 1993). Using in situ hybridization, we tested whether MKP-1 mRNA could be upregulated after the induction of LTP. In control rats, no signal was detectable in the hippocampus; however, we found an increase in MKP-1 mRNA hybridization signals in the ipsilateral dentate gyrus $15 \mathrm{~min}$ after LTP and to a greater extent 1 hr after LTP (Fig. 3). By 3 hr after LTP, the expression of MKP-1 mRNA had returned to basal levels (data not shown). Thus, high-frequency stimulation leads to rapid and sustained induction of MKP-1 mRNA, which is one potential mechanism that may account for a negative feedback loop underlying the rapid dephosphorylation of MAPK/ERKs observed $15 \mathrm{~min}$ after the induction of LTP.

In the next experiment, we tested whether the induction of LTP and the activation of MAPK/ERK resulted in simultaneous ac- tivation of the transcription factor Elk-1. Upon MAPK/ERK activation, phosphorylation of Elk-1 occurs principally on $\mathrm{Ser}^{383}$ and $\operatorname{Ser}^{389}$ residues (Marais et al., 1993). Adjacent sections to those used for $\mathrm{p}-\mathrm{MAPK} / \mathrm{ERK}$ immunocytochemistry were labeled with an antibody that specifically recognizes the $\mathrm{Ser}^{383}$ phosphorylated form of Elk-1 (antiphospho-Ser ${ }^{383}$-Elk-1). In control stimulated animals, constitutive labeling was detectable bilaterally in the dentate gyrus and CA layers, and no change in p-Elk-1 was detectable on the side of the dentate gyrus in which low-frequency stimulation was delivered (Fig. 4). Immediately after the induction of LTP, we observed a marked increase in p-Elk-1 immunolabeling in the granule cell and molecular layers of the dentate gyrus that was restricted to the side of LTP induction (Fig. 4a) and was still detectable 15 min later (Fig. 4a). Densitometric analysis (Fig. 4c) revealed that this increase in p-Elk-1 was significant immediately at the end of the tetanus $(203 \pm 43 \%, n=4, p<0.05)$ and $15 \min$ later $(130 \pm 7 \%, n=$ $4, p<0.05)$, whereas no change was observed after control stimulation. High-magnification shows that p-Elk-1 staining was increased in the nuclei of granule cells and dendrites after LTP (Fig. 4b) compared with the contralateral dentate gyrus in which nuclei of granule cells showed only constitutive labeling. To confirm the specificity of anti-active Elk-1 antibody, we performed Western blots on tissue extracts taken from the dorsal dentate gyrus of control rats and rats in which LTP was induced. p-Elk-1 antibody, which yielded one band of $62 \mathrm{kDa}$, the expected molecular weight for Elk-1, gave increased signals in extracts taken immediately after the tetanus $(199 \pm 60 \%, n=6)$ but not 


\section{MKP-1 mRNA}
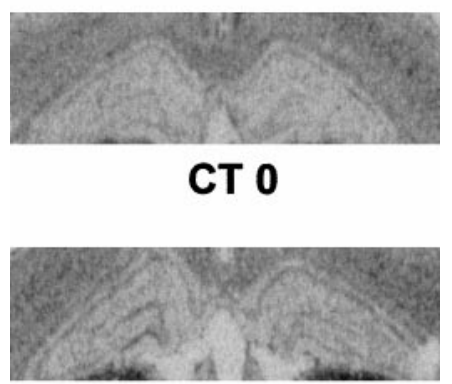

LTP 15

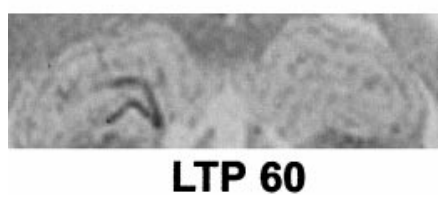

Figure 3. Expression of MKP-1 mRNA after induction of LTP in the dentate gyrus. In situ hybridization shows that MKP-1 is upregulated at LTP 15 and LTP 60 and that the increase is restricted to the potentiated side of the dentate gyrus. No difference was observed in the control stimulated rats at either time point. There were three to four rats in each group.

15 min later $(103 \pm 19 \%, n=3)$ relative to the controls (Fig. $4 d)$, whereas comparable levels of Elk-1 were present in dentate tissue from all groups (Fig. 4d). At $15 \mathrm{~min}$, the absence of an increase in p-Elk-1 with Western blots compared with immunocytochemistry indicates that p-Elk-1 may not be increased in all cells at this time point. Thus, the results show that Elk-1 is hyperphosphorylated after high-frequency stimulation of the perforant path, correlated with the activation and nuclear translocation of the MAPK/ ERKs. In postsynaptic granule cells, phosphorylation of Elk-1 after LTP occurred not only in the nucleus in which it can activate the SRE-DNA regulatory element of IEG promoters but also in the cytoplasm. Although this observation seems intriguing, Elk-1 is described in the adult CNS as a cytoplasmic and nuclear target of activated MAPK/ERK signaling cascade, and our observations in the dentate gyrus after LTP are consistent with the previously described localization and regulation of Elk-1 in the striatum (Sgambato et al., 1998a,b).

\section{Inhibition of MAPK/ERK blocks Elk-1 activation and SRE-regulated gene expression}

The data presented so far support the hypothesis that MAPK/ ERK activation and nuclear translocation do have a role to play in LTP-induced gene expression via the transcription factor Elk-1. If this hypothesis is correct, then inhibition of MAPK/ERK phosphorylation should result in a blockade of Elk-1 phosphorylation and inhibition of LTP-induced SRE-dependent gene expression. To test this, we induced LTP in the presence of an inhibitor of the MAPK kinase MEK, a dual-specific MAPK/ ERK-activating enzyme. The MEK inhibitor SL327 (Favata et al., 1998) was injected intraperitoneally $1 \mathrm{hr}$ before the induction of LTP at a dose of $100 \mathrm{mg} / \mathrm{kg}$, conditions that have been reported to abolish MAPK/ERK activation in CA1 (Atkins et al., 1998). When SL327 was injected, LTP in the dentate gyrus was induced to the same level as in drug vehicle (DMSO)-injected controls, but it decayed rapidly with the slope of the EPSP returning close to baseline levels within $1 \mathrm{hr}$ (Fig. $5 a$ ). Here, we confirm observations made in vitro in the hippocampus that MEK inhibitors induce rapidly decaying LTP (English and Sweatt, 1997; Coogan et al., 1999), adding further strength to the role of MAPK/ERK in long-term synaptic plasticity, by demonstrating the same effect in vivo.

Next, we tested whether SL327 blocks LTP-induced MAPK/ ERK and Elk-1 activation on brain sections from rats killed immediately after the tetanus. We noted that, after the injection of SL327, the level of p-MAPK/ERK immunostaining was lower that in the contralateral side of DMSO-treated rats, suggesting a decrease in the constitutive level of p-MAPK/ERK as reported previously (Atkins et al., 1998). In the LTP experiments, we found that SL327 strongly inhibited both MAPK/ERK (Fig. 5b) and Elk-1 phosphorylation (Fig. 5c). Immediately after the tetanus, increases in p-MAPK/ERK and in p-Elk-1 immunolabeling was observed in all rats injected with DMSO, thus replicating the above results after LTP in noninjected rats. In contrast, immunostaining of p-MAPK/ERK and p-Elk-1 was strongly inhibited in rats injected with SL327 (Fig. 5b,c). The densitometric analysis revealed a significant increase in p-MAPK/ERK (Fig. 5e) and p-Elk-1 (Fig. 5e) staining in the ipsilateral side in DMSO-treated rats (420 \pm 84 and $172 \pm 5 \%$, respectively, $n=3, p<0.05$ in each case), which was not different from the results obtained after LTP in noninjected rats, but was significantly different from the SL327 group $(p<0.05)$. This result indicates that MAPK/ERK activation is required for LTP-induced Elk-1 phosphorylation. We then assessed whether SL327 blocks zif268 expression using in situ hybridization on adjacent sections from those used for immunocytochemistry (immediately after the tetanus, DMSO, $n=3$; SL327, $n=3$ ) and in brains taken $1 \mathrm{hr}$ after the tetanus (DMSO, $n=3$; SL327, $n=3$ ). Under these conditions, there was no change in constitutive expression of zif 268 mRNA. In accordance with the results shown in Figure 1, a marked increase in the expression of zif 268 was observed immediately and $1 \mathrm{hr}$ after the tetanus in DMSO-injected rats (Fig. 5d). When SL327 was injected, we found a complete blockade of LTP-induced expression of zif268 mRNA (Fig. 5d). Surprisingly, not only did SL327 block zif 268 induction, but in two of the three rats at $1 \mathrm{hr}$ after tetanus, the combination of SL327 injections with the tetanus resulted in downregulation of zif 268 in the stimulated side (Fig. $5 d$ ). Because the phosphorylation state of both Elk-1 and CREB is linked to a balance between kinase and phosphatase activity, it is possible that, under SL327, a strong calcium-induced phosphatase activity induced by LTP leads to downregulation of zif268. Together, these findings provide a molecular substrate for the action of MAPK/ERK on long-term synaptic plasticity by showing direct control on gene regulation, a hypothesis that has been alluded to in many recent studies (English and Sweatt, 1997; Impey et al., 1998a, 1999) but until now has not been demonstrated. There were of course some differences between animals. Most interesting was the observation of a slight residual increase in p-MAPK/ ERK immunoreactivity in some rats after injection of SL327 (Fig. $6 a-d)$, as shown in the densotimetric analysis (Fig. 5e). Immunocytochemistry showed that this increase was restricted to dendrites, with very little, if any, nuclear staining (Fig. $6 d$ ). When this occurred, p-Elk-1 was greatly reduced compared with DMSOtreated rats (Fig. $6 b-e$ ). Despite the slight activation of MAPK/ ERK in dendrites, there was no transcriptional regulation of zif268 (Fig. 6c-f), suggesting that strong MAPK/ERK activation and its nuclear translocation is necessary for SRE-driven gene regulation. 
a

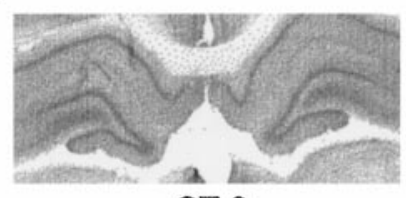

CT 0

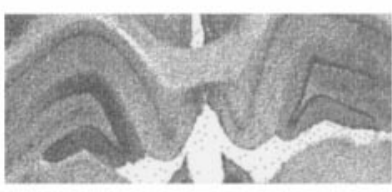

LTP 0

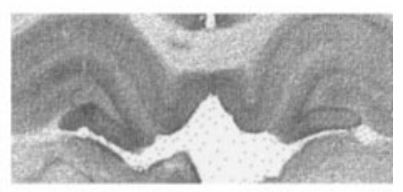

LTP 15

b

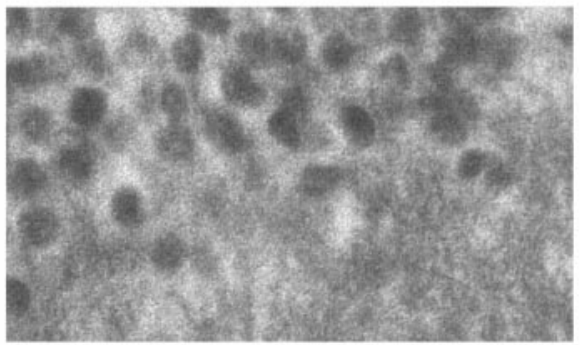

ipsilateral induction of LTP. $a$, Immunocytochemical images in the ipsilateral dentate gyrus shows an increase in p-Elk-1 at LTP 0 and to a lesser extent at LTP 15 compared with the contralateral side. No change was observed in the control groups. $b$, High magnification $(630 \times)$ of these images shows p-Elk-1 labeling in both cell bodies and dendrites in the ipsilateral dentate gyrus. $c$, Densitometric quantification of immunolabeling shows that p-Elk-1 is significantly increased at LTP 0 and LTP 15. $d$, Western blots of p-Elk-1 confirm immunohistochemical results showing increased p-Elk-1 at LTP 0 (top panel), and this increase was only observed with the activated form, with no change in total Elk-1 (bottom panel).
C

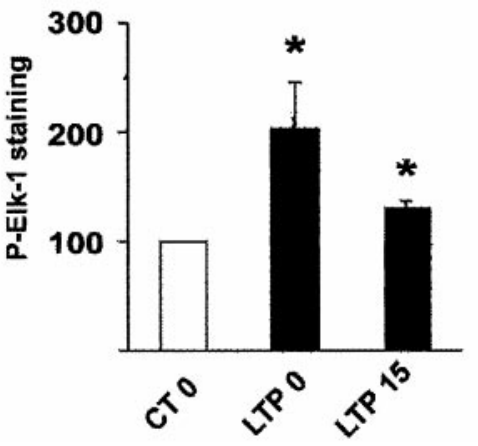

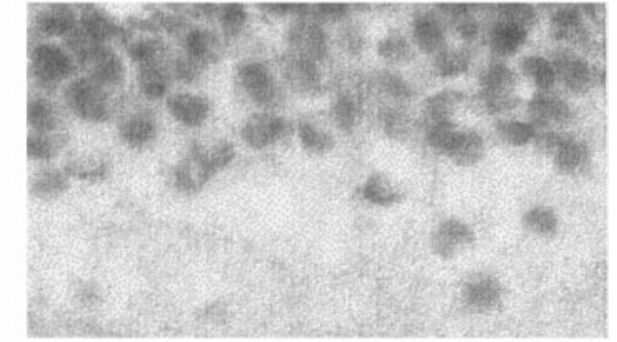

contralateral

d

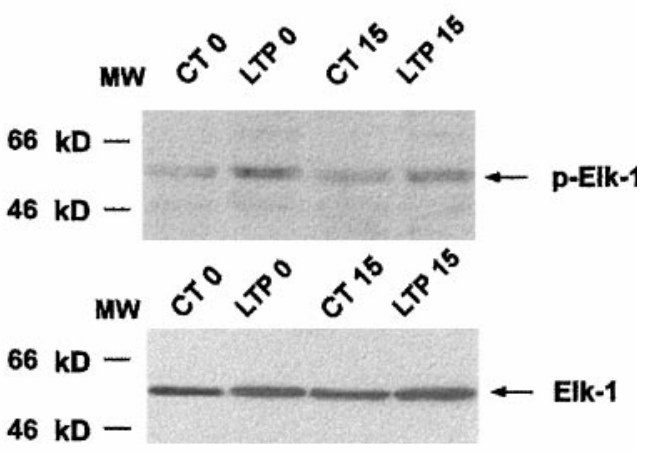

\section{Inhibition of MAPK/ERK also blocks LTP-induced CREB activation}

Several studies have demonstrated that MAPK/ERK can also activate CREB via phosphorylation of the CREB kinase Rsk2 (Xing et al., 1996; Impey et al., 1998a) and that LTP-driven CRE-LacZ expression in the CA1 slice is blocked by the MEK inhibitor PD98059 (Impey et al., 1998a). In vivo, activation of CREB was described recently after LTP in the dentate gyrus (Schulz et al., 1999). Using Western blots, we have confirmed here that an increase in phosphorylated CREB occurs after LTP in the dentate gyrus $(178 \pm 22 \%, n=5, p<0.05$ compared with controls) (Fig. 7c), and the time course was similar to that observed for Elk-1 phosphorylation. This was also clear from sections adjacent to those used for p-MAPK/ERK and p-Elk-1 staining and labeled with $\mathrm{p}$-CREB-specific antibody, showing that p-CREB increases in the nuclei of granule cells immediately at the end of the tetanus (Fig. 7a). Injection of SL327 before the tetanus strongly inhibited the LTP-induced increase in p-CREB in granule cell nuclei (Fig. $7 f$ ). Together, the results strongly suggest that activated MAPK/ERK can regulate gene expression after nuclear translocation and the phosphorylation of at least two transcription factors, CREB and Elk-1.

\section{DISCUSSION}

Previous studies have indicated a critical role for the MAPK/ ERK cascade in models of neuronal plasticity, such as long-term facilitation in Aplysia sensory neurons (Martin et al., 1997) and LTP in CA1 of the hippocampus (for review, see Impey et al., 1999). Because the maintenance of these forms of plasticity re- quires gene transcription (Nguyen et al., 1994; Bartsch et al., 1995), we have addressed the issue of whether and how activation of MAPK/ERK can mediate gene induction in LTP by measuring the expression of the IEG zif268, known to be strongly activated in LTP. Our results support the idea that MAPK/ERK phosphorylation and its subsequent nuclear translocation is an essential step in mediating gene induction required for longlasting LTP in the dentate gyrus in vivo. We further demonstrate that Elk-1 is a key component between MAPK/ERK activation and LTP-dependent gene induction. The MAPK/ERK-Elk-1 cascade has been shown to be activated by electrical stimulation of corticostriatal fibers (Sgambato et al., 1998a,b), and here we demonstrate for the first time its role in LTP-dependent gene induction. Our study shows that MAPK/ERK and the two downstream transcription factors, Elk-1 and CREB, are rapidly phosphorylated in nuclei of dentate granule cells after the induction of LTP. Inhibition of MEK, the upstream MAPK/ERK kinase, blocked LTP-induced phosphorylation of MAPK/ERK and, conjointly, the phosphorylation of Elk-1 and CREB, resulting in a rapidly decaying LTP. These findings support the model that MAPK/ERK activation and nuclear translocation are essential to the coactivation of the two transcription factors. Elk-1 is one of the main nuclear targets of activated MAPK/ERK and has been shown to be newly phosphorylated on $\mathrm{Ser}^{383}$ and $\mathrm{Ser}^{389}$ by growth factors (Marais et al., 1993), leading to SRE-driven gene transcription in cell cultures (for review, see Wasylyk et al., 1998). The SRE, together with flanking DNA sequences, serves as a site of assembly of multiprotein complexes, including a dimer of the 
a

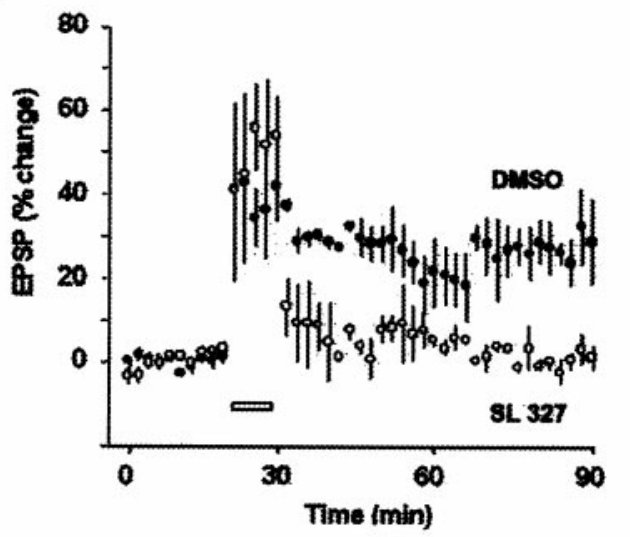

b

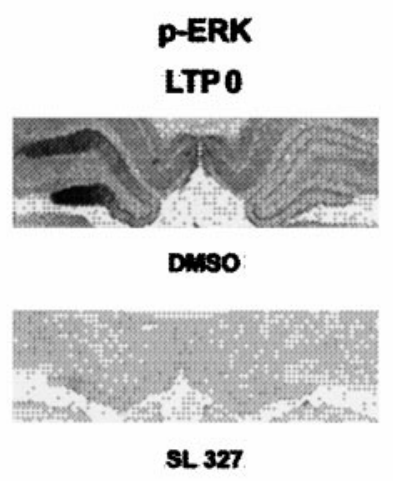

C

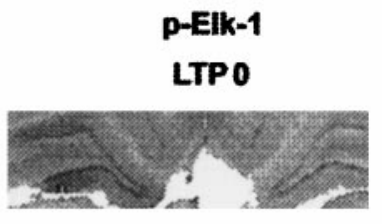

Dinso

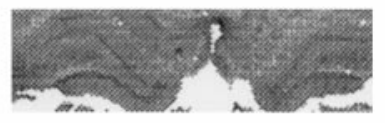

SL. 327

P-ERK

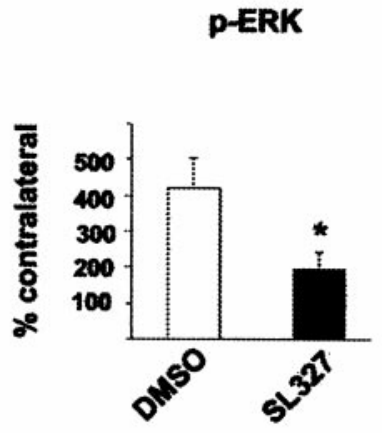

d

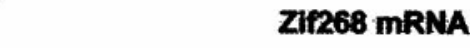

LTPO.

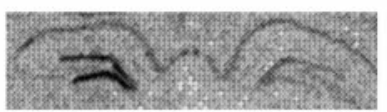

Dimso

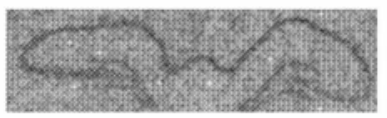

8L. 327

p-EIk-1

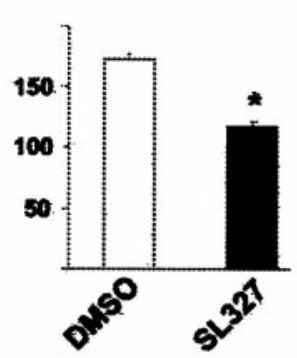

LTP 60

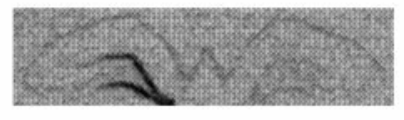

Disso

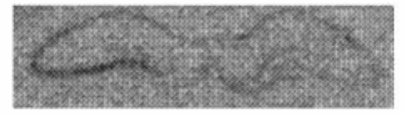

SL 327

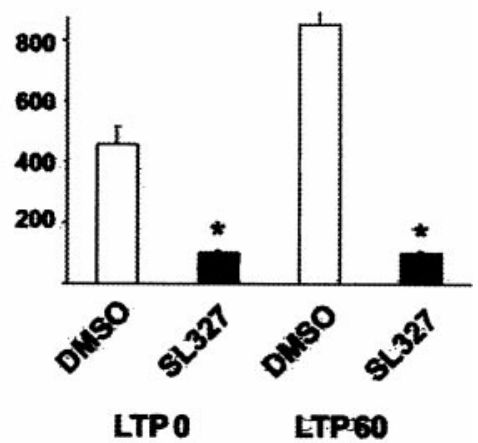

Figure 5. Inactivation of MEK with SL327 results in disruption of the downstream activation of p-MAPK/ERK, p-Elk-1, and zif268 mRNA expression induced by LTP. $a$, After the induction of LTP in the presence of SL327, the EPSP declined to basal levels within $60 \mathrm{~min}$, and there was no effect on LTP after injections of DMSO. $b$, Immunocytochemical images of p-MAPK/ ERK in the dentate gyrus at LTP 0 shows that DMSO had no effect on LTP-induced p-MAPK/ERK, whereas injections of SL327 resulted in inhibition of p-MAPK/ ERK. $c$, Similarly, p-Elk-1 was also inhibited by SL327 at LTP 0, with no effect on LTP-induced activation of p-Elk-1 after DMSO. $d$, In situ hybridization images of zif268 at LTP 0 and LTP 60 in rats injected with either SL327 or DMSO. Zif268 was upregulated in the potentiated dentate gyrus in the DMSO control group at both time points, whereas in the SL327 group, LTPinduced upregulation of zif268 was blocked at both time points. $e$, Quantification of densitometric measures of p-MAPK/ERK and p-Elk-1 at LTP 0 and optical density measures of the expression of zif $268 \mathrm{mRNA}$ at LTP 0 and LTP 60 confirm blockade of MAPK/ERK and Elk-1 phosphorylation, and of zif 268 induction in the presence of SL327 (asterisks indicate significant difference from DMSO controls). serum response factor (Treisman, 1986; Norman et al., 1988; Schröter et al., 1990) and a protein of the ternary complex factor family, such as Elk-1 (for review, see Treisman, 1995), and this site is present in the promoter region of many IEGs, including zif268. Our results, which show that inhibition of MAPK/ERK phosphorylation and the resulting inhibition of Elk-1 prevents the transcriptional activation of zif268, support the model that activation of the MAPK/ERK signaling pathway targets nuclear Elk-1 to control SRE-mediated gene expression in LTP. Because the stress-induced MAPKs p38 and JNK are not affected by the MEK inhibitor, it highlights the role of the MAPK/ERK subfamily in Elk-1 phosphorylation in LTP. We also found that dendritic Elk-1 was phosphorylated after LTP as has been reported in the striatum after cortical stimulation (Sgambato et al., 1998a,b), and this was blocked by inhibition of MEK. Although our study does not address the function of dendritic Elk-1 protein in LTP, together the results suggest a role as a local cytoplasmic substrate of activated MAPK/ERKs, which may be implicated in relaying the glutamatergic receptor signal to different intracellular compartments, including the nucleus. Interestingly, the fact that, in the presence of SL327, LTP in the dentate gyrus decayed more rapidly than one would expect for a cascade involved in the protein synthesis-dependent phase of LTP, suggests that MAPK/ ERK may also contribute to an earlier phase of LTP and this may well involve one of the many cytoplasmic substrates of MAPK/ ERK, such as dendritic Elk-1.

Transcriptional regulation in LTP is classically attributed to CREB, which binds to the CRE site present in the promoter regions of several IEGs, and CREB appears to be critical for the maintenance of LTP and the formation of certain forms of 
Figure 6. High magnification of phosphorylated MAPK/ERK and Elk-1, and expression of zif268 at LTP 0 in the presence of DMSO or SL327. $a$, In the presence of DMSO, there is heavy labeling of p-MAPK/ERK in both dendrites and the cell bodies of granule cells. In addition, there is hyperphosphorylation of Elk-1 (b) and an upregulation of zif268 mRNA (c). $d$, In some cases, there was some labeling of p-MAPK/ERK in the SL327treated rats, but this was restricted to the dendrites. In these rats, p-Elk-1 was greatly reduced $(e)$, and there was no upregulation of zif268 mRNA $(f)$, suggesting the need for translocation of MAPK/ERK to the nucleus to phosphorylate Elk-1 and upregulate zif268.
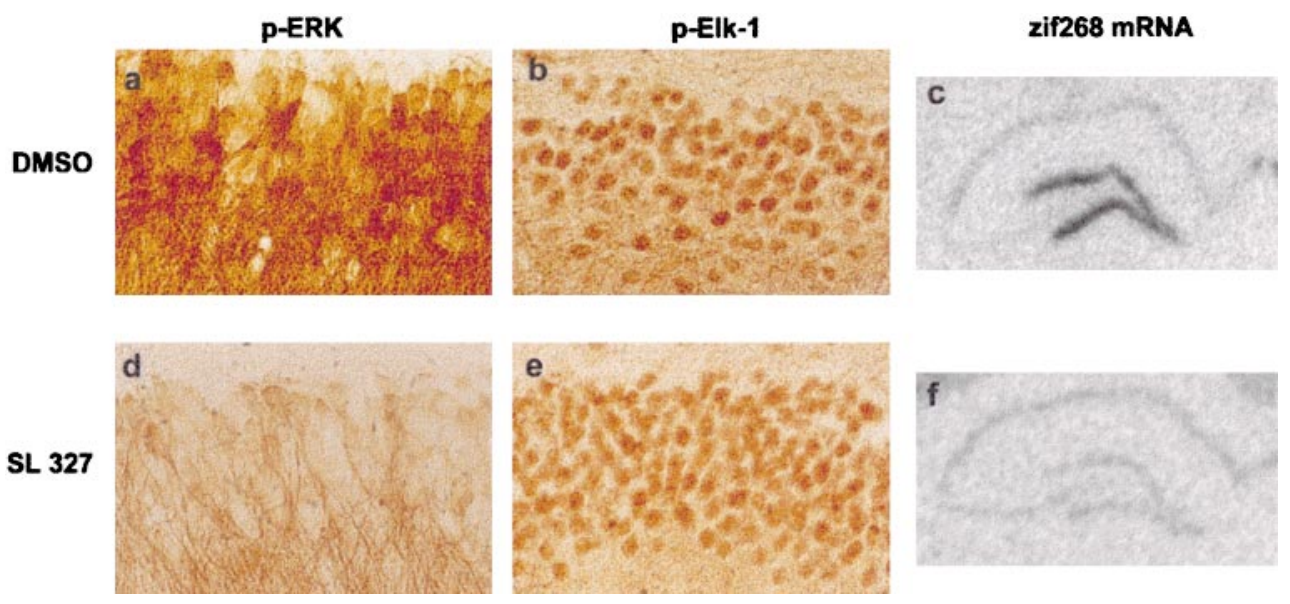

a
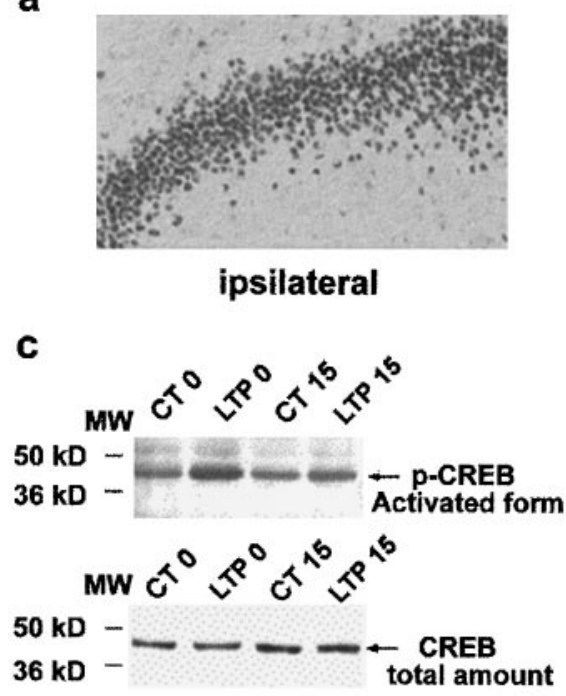

e

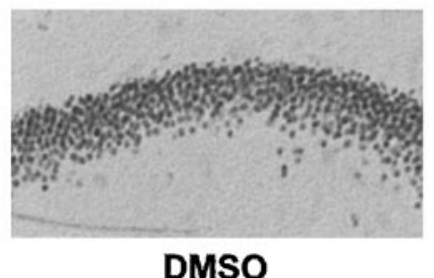

b

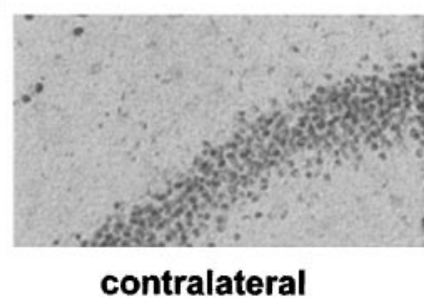

d

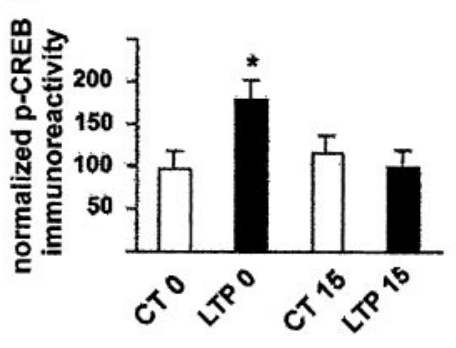

f

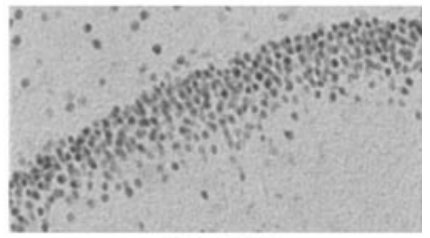

SL 327

LTP and in the presence of SL327. $a, b$, An increase in p-CREB labeling was observed on the potentiated side at LTP 0 compared with the contralateral dentate gyrus. $c, d$, Western blots confirm that p-CREB is increased only at this time point compared with control rats, and quantification showed that this was a significant increase. $e, f$, The level of p-CREB was greatly attenuated in SL327-treated rats compared with DMSO controls.

long-term memory (Bourtchuladze et al., 1994). Consistent with a recent report (Schulz et al., 1999), we show that, after the induction of LTP, CREB was phosphorylated in dentate granule cell nuclei. In addition, we show here that it follows a similar time course to that of MAPK/ERK and Elk-1 phosphorylation, and it is blocked by inhibition of MEK. The data here add a further element to the previous suggestion of MAPK/ERK-dependent CRE-driven expression in LTP in CRE-LacZ transgenic mice in vitro (Impey et al., 1996, 1998a), and this presumably occurs via a CREB kinase of the Rsk family resulting in phosphorylation of CREB (Xing et al., 1996; Impey et al., 1998a). Together, we propose that the signal transduction mechanisms underlying LTP-dependent transcription involves two parallel signaling pathways, the direct MAPK/ERK-Elk-1 signaling pathway mediating SRE-dependent transcription and the indirect MAPK/ERK-
Rsk-CREB pathway mediating CRE-dependent transcription. It is possible that these transcription factors cooperate to activate genes, at least those carrying both CRE and SRE. The analysis of $c$-fos expression in transgenic mice models showing that the combination of these two DNA-binding elements is crucial for gene transcription (Robertson et al., 1995) suggests that this may well be the case. The zif 268 promoter contains two putative CRE sites but multiples SREs and is therefore likely to be strongly controlled by the MAPK/ERK-Elk-1 pathway. Under normal conditions, it is possible that the strong activation of zif268 in LTP is attributable to the combined activation of both Elk-1 and CREB by MAPK/ERK. This may occur via their interactions with the coactivator CREB binding protein, which facilitates more efficient transcription through multiple contacts with the basal transcriptional machinery (Kwok et al., 1994; Janknecht and 
Nordheim, 1996) and plays a key role in calcium-mediated gene transcription in cellular models of plasticity (Hardingham et al., 1999; Hu et al., 1999).

The fact that MAPK/ERK, CREB, and Elk-1 are only transiently activated suggests that there may be a mechanism that dephosphorylates these proteins. As postulated in a recent model of the dynamics of interactions in signaling systems (Bhalla and Iyengar, 1999), a feedback loop may involve phosphatase activity. Our findings that the mRNA encoding the MAPK/ERK phosphatase MKP-1 is overexpressed in granule cells after LTP is entirely consistent with this prediction. Although not the only possibility, the activation of MKP-1 for between 1 and $3 \mathrm{hr}$ after LTP thus provides one example of a feedback mechanism that is likely to function in this way, resulting in deactivation of CREB and Elk-1, and subsequently that of IEG transcription.

In summary, these data provide evidence that, in the transcriptional events associated with LTP, the MAPK/ERK signaling cascade plays an important role in regulating genes controlled not only by CRE via phosphorylation of CREB (Impey et al., 1998a) but also by SRE via phosphorylation of Elk-1. Together with previous findings, we propose that the MAPK cascade controls diverse transcriptional responses induced by LTP through two distinct pathways, one targeting CRE-mediated transcription via the activation of CREB, the second pathway controlling SREmediated transcription via phosphorylation of the transcription factor Elk-1.

\section{REFERENCES}

Atkins CM, Selcher JC, Petraitis JJ, Tzaskos JM, Sweatt JD (1998) The MAPK cascade is required for mammalian associative learning. Nat Neurosci 1:602-609.

Barnes CA (1979) Memory deficits associated with senescence: a neurophysiological and behavioral study in the rat. J Comp Physiol Psychol 93:74-104.

Bartsch D, Ghirardi M, Skehel PA, Karl KA, Herder SP, Chen M, Bailey CH, Kandel ER (1995) Aplysia CREB2 represses long-term facilitation: relief of repression converts transient facilitation into long-term functional and structural change. Cell 83:979-992.

Bhalla US, Iyengar R (1999) Emergent properties of networks of biological signaling pathways. Science 283:381-387.

Bliss TVP, Collingridge GL (1993) A synaptic model of memory: longterm potentiation in the hippocampus. Nature 361:31-39.

Blum S, Morre AN, Adams F, Dash PA (1999) Mitogen-activated protein kinase cascade in the CA1/CA2 subfield of the dorsal hippocampus is essential for long-term spatial memory. J Neurosci 19:3535-3544.

Bourtchuladze R, Frenguelli B, Blendy J, Cioffi D, Schutz G, Silva AJ (1994) Deficient long-term memory in mice with a targeted mutation of the cAMP-responsive element-binding protein. Cell 79:59-68.

Charles CH, Sun H, Lau LF, Tonks NK (1993) The growth factorinducible immediate-early gene 3CH134 encodes a protein-tyrosinephosphatase. Proc Natl Acad Sci USA 90:5292-5296.

Chen RH, Sarneki C, Blenis J (1992) Nuclear localization and regulation of erk- and rsk-encoded protein kinases. Mol Cell Biol 12:915-927.

Cole AJ, Saffen DW, Baraban JM, Worley PF (1989) Rapid increase of an immediate early gene messenger RNA in hippocampal neurons by synaptic NMDA receptor activation. Nature 340:474-476.

Coogan AN, O'Leary DM, O'Connor JJ (1999) P42/44 MAP kinase inhibitor PD98059 attenuates multiple forms of synaptic plasticity in rat dentate gyrus. J Neurophysiol 81:103-110.

Doyère V, Laroche S (1992) Linear relationship between the maintenance of hippocampal long-term potentiation and retention of an associative memory. Hippocampus 2:39-48.

English JD, Sweatt JD (1996) Activation of p42 mitogen-activated protein kinase in hippocampal long-term potentiation. J Biol Chem 271:24329-24332.

English JD, Sweatt JD (1997) Requirement for the mitogen-activated protein kinase cascade in hippocampal long-term potentiation. J Biol Chem 272:19103-19106.

Favata M, Horiuchi KY, Manos EJ, Daulerio AJ, Stradley DA, Feeser
WS, Van Dyk DE, Pitts WJ, Earl RA, Hobbs F, Copeland RA, Magolda RL, Scherle PA, Trzaskos JM (1998) Identification of a novel inhibitor of mitogen-activated protein kinase kinase. J Biol Chem 273:18623-18632.

Frey U, Morris RGM (1997) Synaptic tagging: implications for the late maintenance of hippocampal long-term potentiation. Trends Neurosci 21:181-188.

Hardingham GE, Chawla S, Cruzalegui FH, Bading H (1999) Control of recruitment of transcription-activating function of CBP determines gene regulation by NMDA receptors and L-type calcium channels. Neuron 22:789-798.

Hipskind RA, Rao VN, Mueller CGF, Reddy ESP, Nordheim A (1991) Ets-related protein Elk-1 is homologous to the c-fos regulatory factor p62TCF. Nature 354:531-534.

Hipskind RA, Baccarini M, Nordheim A (1994) Transient activation of RAF-1, MEK and ERK2 coincides kinetically with ternary complex factor phosphorylation and immediate-early gene promoter activity in vivo. Mol Cell Biol 14:6219-6231.

Hu SC, Chrivia J, Ghosh A (1999) Regulation of CBP-mediated transcription by neuronal calcium signaling. Neuron 22:799-808.

Impey S, Mark M, Villacres EC, Chavkin C, Storm DR (1996) Induction of CRE-mediated gene expression by stimuli that generate long-lasting LTP in area CA1 of the hippocampus. Neuron 16:973-982.

Impey S, Obrietan K, Wong ST, Poser S, Yano S, Wayman G, Deloulme JC, Chan G, Storm DR (1998a) Cross talk between ERK and PKA is required for $\mathrm{Ca}^{2+}$ stimulation of CREB-dependent transcription and ERK nuclear translocation. Neuron 21:869-883.

Impey S, Smith DM, Obrietan K, Donahue R, Wade C, Storm DR (1998b) Stimulation of cAMP response element (CRE)-mediated transcription during contextual learning. Nat Neurosci 1:595-601.

Impey S, Obrietan K, Storm DR (1999) Making new connections: role of ERK/MAP kinase signaling in neuronal plasticity. Neuron 23:11-14.

Janknecht R, Nordheim A (1996) Map kinase-dependent transcription coactivation by Elk-1 and cofactor CBP. Biochem Biophys Res Commun 21:831-837.

Janknecht R, Zinck R, Ernst WH, Nordheim (1994) A functional dissection of the transcription factor, Elk-1. Oncogene 9:1273-1278.

Kwok RPS, Lundblad JR, Chrivia JC, Richards JP, Bachinger HP, Brennan RG, Roberts SGE, Green MR, Goodman RH (1994) Nuclear protein CBP is a coactivator for the transcription factor CREB. Nature 370:223-226.

Laroche S, Doyère V, Bloch V (1989) Linear relation between the magnitude of long-term potentiation in the dentate gyrus and associative learning in the rat $\mathrm{A}$ demonstration using commissural inhibition and local infusion of an $N$-methyl-D-aspartate antagonist. Neuroscience 28:375-386.

Lenormand P, Sardet C, Pages G, L'Allemain G, Brunet A, Pouyssegur J (1993) Growth factors induce nuclear translocation of MAP kinase (p42mapk and p44mapk) but not their activator MAP kinase kinase (p56mapk) in fibroblasts. J Cell Biol 122:1079-1088.

Marais R, Wynne J, Treisman R (1993) The SRF accessory protein ELK-1 contains a growth factor-regulated transcriptional activation domain. Cell 73:381-393.

Martin KC, Michael D, Rose JC, Barad M, Casadio A, Zhu H, Kandel ER (1997) MAP kinase translocates into the nucleus of the presynaptic cell and is required for long-term facilitation in Aplysia. Neuron 18:899-912.

Nguyen PV, Abel T, Kandel ER (1994) Requirements of a critical period of transcription for induction of a late phase of LTP. Science 265:1104-1107.

Norman C, Runswick M, Pollock R, Treisman R (1988) Isolation and properties of cDNA clones encoding SRF, a transcription factor that binds to the c-fos serum response element. Cell 55:989-1003.

Otani S, Marshall CJ, Tate WP, Goddard GV, Abraham WC (1989) Maintenance of long-term potentiation in rat dentate gyrus requires protein synthesis but not messenger RNA synthesis immediately posttetanization. Neuroscience 28:519-526.

Roberson ED, English JD, Adams JP, Selcher JC, Kondratick C, Sweatt JD (1999) The mitogen-activated protein kinase cascade couples PKA and $\mathrm{PKC}$ to cAMP response element binding protein phosphorylation in area CA1 of the hippocampus. J Neurosci 19:4337-4348.

Robertson LM, Kerpolia TK, Vendreli M, Luk D, Smeyne RJ, Bocchiara C, Morgan JI, Curran T (1995) Regulation of c-fos expression in transgenic mice requires multiple interdependent transcription control elements. Neuron 14:241-252. 
Schröter H, Mueller CGF, Meese K, Nordheim A (1990) Synergism in ternary complex formation between the dimeric glycoprotein $\mathrm{p} 67^{\text {srf }}$ polypeptide $\mathrm{p} 62^{\text {tcf }}$ and the c-fos serum response element. EMBO J 9:1123-1130.

Schulz S, Siemer H, Krug M, Höllt V (1999) Direct evidence for biphasic cAMP responsive element-binding protein phosphorylation during long-term potentiation in the rat dentate gyrus in vivo. J Neurosci 19:5683-5692.

Sgambato V, Vanhoutte P, Pagès C, Rogard M, Hipskind RA, Besson MJ, Caboche J (1998a) In vivo expression and regulation of Elk-1, a target of the extracellular-regulated kinase signaling pathway, in the adult rat brain. J Neurosci 18:214-226.

Sgambato V, Pagès C, Rogard M, Besson MJ, Caboche J (1998b) Extracellular signal-regulated kinase (ERK) controls immediate early gene induction on corticostriatal stimulation. J Neurosci 18:8814-8825.

Soderling TR, Derkach VA (2000) Postsynaptic protein phosphorylation and LTP. Trends Neurosci 23:75-80.

Sun P, Enslen H, Myung PS, Maurer RA (1993) Differential activation of CREB by $\mathrm{Ca}^{2+} /$ calmodulin-dependent protein kinases type II and type IV involves phosphorylation of a site that negatively regulates activity. Genes Dev 8:2527-2539.
Treisman R (1986) Identification of a protein-binding site that mediates the transcriptional response of the c-fos gene to serum factors. Cell 46:657-674.

Treisman R (1995) Journey to the surface of the cell: fos regulation and the SRE. EMBO J 14:4905-4913.

Treisman R (1996) Regulation of transcription by MAP kinase cascade. Curr Opin Cell Biol 8:205-215.

Vanhoutte P, Barnier JV, Guibert B, Pagès C, Besson MJ, Hipskind RA, Caboche J (1999) Glutamate induces phosphorylation of Elk-1 and CREB, along with c-fos activation via an extracellular signal-regulated kinase-dependent pathway in brain slices. Mol Cell Biol 19:136-146.

Wasylyk B, Hagman J, Gutierrez-Hartmann A (1998) Ets transcription factors/nuclear effectors of the Ras-MAP-kinase signaling pathway. Trends Biol Sci 23:213-216.

Wisden W, Errington ML, Williams S, Dunnett SB, Waters C, Hitchcock D, Evan D, Bliss TVP, Hunt SP (1990) Differential expression of immediate early gene in the hippocampus and spinal cord. Neuron 4:603-614.

Xing J, Ginty DD, Greenberg ME (1996) Coupling of the RAS-MAPK pathway to gene activation by RSK2, a growth factor-regulated CREB kinase. Science 273:959-963. 